\title{
Using the egg parasitoid Anastatus bifasciatus against the invasive brown marmorated stink bug in Europe: can non-target effects be ruled out?
}

\author{
Judith M. Stahl ${ }^{1,2} \cdot$ Dirk Babendreier $^{1} \cdot$ Tim Haye $^{1}$ \\ Received: 16 January 2018 / Revised: 8 March 2018 / Accepted: 15 March 2018 / Published online: 21 March 2018 \\ (c) The Author(s) 2018
}

\begin{abstract}
The brown marmorated stink bug, Halyomorpha halys (Stål) (Hemiptera: Pentatomidae), has been causing massive damage to various fruit and vegetable crops after its arrival in the USA, and more recently in Europe. To provide an alternative control measure to pesticides, the native egg parasitoid Anastatus bifasciatus (Geoffroy) (Hymenoptera: Eupelmidae) was considered as a candidate biological control agent for inundative releases in Europe. In the risk assessment study presented here, all nine heteropteran and 14 out of 19 tested lepidopteran non-target species produced viable A. bifasciatus offspring. The proportion of $A$. bifasciatus females producing offspring did not differ between non-target and target for 19 out of the 28 non-target species. Larger host eggs corresponded to increased female-biased sex ratio of the offspring as well as an increase in size, particularly for females, with hind tibia lengths varying from $645.5 \pm 46$ to $1084 \pm 28.5 \mu \mathrm{m}$. Larger females were also found to have higher offspring production and increased life expectancy. The results of this study confirmed the polyphagous nature of A. bifasciatus and suggest that a number of non-target species, including Lepidoptera of conservation interest, may be attacked in the field. Thus, non-target effects cannot entirely be ruled out, but more information is needed from semi-field and field studies to fully assess potential environmental risks due to inundative releases of this native parasitoid.
\end{abstract}

Keywords Biological control $\cdot$ Egg parasitoids $\cdot$ Risk assessment $\cdot$ Fundamental host range $\cdot$ Halyomorpha halys

\section{Key message}

- Potential non-target effects following inundative releases of the European parasitoid Anastatus bifasciatus against the invasive Halyomorpha halys are unknown.

- No-choice tests with 9 heteropteran and 19 lepidopteran non-target species were conducted in the laboratory.

Communicated by D. C. Weber.

Electronic supplementary material The online version of this article (https://doi.org/10.1007/s10340-018-0969-x) contains supplementary material, which is available to authorized users.

Judith M. Stahl

j.stahl@cabi.org

1 CABI, Rue des Grillons 1, 2800 Delémont, Switzerland

2 Institute of Ecology and Evolutionary Biology, University of Bremen, Leobener Str. NW2, 28359 Bremen, Germany
- Twenty-three non-target species were suitable hosts for A. bifasciatus; the proportion of females producing offspring did not differ between non-target and target for 19 out of 28 tested species.

- Non-target effects due to spill-over cannot be ruled out, and further semi-field and field tests are necessary.

\section{Introduction}

The brown marmorated stink bug (BMSB), Halyomorpha halys (Stål) (Hemiptera: Pentatomidae), is an Asian species invasive in North America and Europe, and recently established in South America (Faúndez and Rider 2017). Whereas the introduction to North America occurred in the mid-1990s (Hoebeke and Carter 2003), in Europe H. halys probably arrived in the early 2000s with first individuals found in the area of Zurich, Switzerland (Wermelinger et al. 2008; Haye et al. 2014a, b). Since its arrival, it has established in many other European countries, and bioclimatic models suggest that there is substantial potential 
for further spread (Kriticos et al. 2017; Zhu et al. 2017). The wide host range of this exotic pest includes economically important crops such as fruit trees, vegetables and leguminous crops (Kobayashi 1967; Lee et al. 2013). In the USA, $H$. halys has been causing massive damage to various crops, e.g. apples, peaches, sweet corn and beans (Kuhar et al. 2012; Leskey et al. 2012a, b; Nielsen and Hamilton 2009). In Europe and Eurasia, including northern Italy and western Georgia, severe damage has been observed in pear and hazelnut orchards (Bosco et al. 2017; Maistrello et al. 2017).

Current control strategies mainly rely on the application of broad-spectrum insecticides (Leskey et al. 2012a, b; Nielsen et al. 2008; Kuhar and Kamminga 2017). These, however, often lack efficacy and their increased application led to a resurgence of secondary pests such as woolly apple aphids or European red mite. Populations of those pests were well regulated by natural enemies before the arrival of $H$. halys (Leskey et al. 2012a). This indicates severe pressure on the often well-established IPM systems in European fruit production, which generally rely on selective pesticides that are not harmful to many natural enemies. Hence, the development and implementation of environmentally sound control methods, such as biological control, are urgently needed to provide an alternative solution against $H$. halys in Europe (Haye et al. 2015).

In China, Korea, and Japan, where the pest originates, its populations are primarily regulated by egg parasitoids in the genera Trissolcus (Hymenoptera: Scelionidae) and Anastatus (Hymenoptera: Eupelmidae) (Arakawa and Namura 2002; Lee et al. 2013; Talamas et al. 2015). In particular, Trissolcus japonicus (Ashmead) causes high parasitism in $H$. halys (Yang et al. 2009; Zhang et al. 2017) and thus is being considered as a classical biological control agent. However, if it appears that it is not regarded as specific to the target host and introductions may have adverse effects, augmentative (inoculative or inundative) use of parasitoids native to the invaded area may provide an alternative control strategy (Haye et al. 2015; Roversi et al. 2016).

Studies searching for native egg parasitoids adopting the invasive $H$. halys as new host have been conducted in the USA and Europe exposing viable or freeze-killed sentinel H. halys eggs (Abram et al. 2017). In Switzerland and Italy, parasitoids reared from those sentinel $H$. halys eggs exposed on trees mainly in or in the vicinity of fruit orchards and vineyards were Ooencyrtus telenomicida (Vassiliev) (frozen eggs) (Roversi et al. 2016), Trissolcus cultratus (Mayr) (frozen eggs), and Anastatus bifasciatus (Geoffroy) (viable and frozen eggs) (Haye et al. 2015). The latter is the most common parasitoid reared from sentinel $H$. halys eggs in the field. This makes it a candidate for inundative biological control, where large numbers of natural enemies are released for immediate control of a damaging pest population.
The majority of Anastatus spp. are primary endoparasitoids of various insect orders (Askew 2005; Jones 1988) such as Hemiptera, Lepidoptera, Blattodea (Narasimham and Sankaran 1982), Orthoptera and Mantodea (Askew 2005). In the past, Anastatus sp. (later identified as A. japonicus (Hayat 1975)) was released alongside other parasitoids in the USA against the gypsy moth (Crossman 1925), and several Anastatus species are currently being tested or used against various pests in different crops around the world. In Australian macadamia orchards, Anastatus sp. is used for augmentative biological control of the fruitspotting bug Amblypelta nitida Stål and the banana spotting bug A. lutescens lutescens Distant (Hemiptera: Coreidae) (Fay and De Faveri 1997; Govender 2015; Huwer et al. 2011). In Nepal, Anastatus sp. was released against the citrus green stink bug Rhynchocoris humeralis (Thunberg) (Hemiptera: Pentatomidae) (Shrestha 2011). In China, Anastatus japonicus Ashmead has been released for several decades to control the lychee stink bug Tessaratoma papillosa Drury (Hemiptera: Pentatomidae) (Chen et al. 1990; Huang et al. 1974). Due to its success, Anastatus sp. was also mass-released against $H$. halys in the Beijing area, achieving parasitism rates of more than 60\% (Hou et al. 2009).

A similar approach could also be possible in Europe, but the knowledge of the biology and ecology of A. bifasciatus in Europe is scarce. Genduso (1977) studied A. bifasciatus on Gonocerus acuteangulatus (Goeze) (Hemiptera: Coreidae) and demonstrated that the parasitoid completed four generations per year on the island of Sicily, Italy. The remaining literature for $A$. bifasciatus consists primarily of host records from across Europe, including more than 30 species in the orders Hemiptera and Lepidoptera (e.g. Herting and Simmonds 1976; Genduso 1977; Jones 1988; compiled by Noyes 2014).

Concerns regarding the safety of classical biological control using invertebrates, particularly the impact on nontarget species, have been discussed intensively. As a result, procedures to select the safest biological control agent have been developed that assess the risks they pose beforehand (Bigler et al. 2006; Barratt et al. 2010; Van Lenteren et al. 2006). Lynch et al. (2001) reported that far more inundative releases have led to population-level non-target effects than classical biological control-although some of these effects were only localized and short term. However, their focus was primarily on exotic biological control agents, whereas inundative releases typically involve native natural enemies. Using native natural enemies instead of exotic ones reduces the potential risks of biological control considerably, since the agents are already naturally present. However, continuous inundative releases of native generalist biological control agents can also lead to non-target effects due to overflow into adjacent habitats (van Lenteren and Loomans 2006) and thus, endangered and beneficial species within those 
habitats could be at risk. Inundative releases of native parasitoids could further facilitate apparent competition between the native and exotic host sharing the same natural enemies (Holt 1977; Holt and Bonsall 2017). Consequently, the potential risks associated with inundative releases should be assessed even for native natural enemies.

The objectives of the present study were to determine the potential risks of inundative releases of $A$. bifasciatus for non-target species and to investigate whether their suitability differs from those of the target $H$. halys.

\section{Materials and methods}

\section{Rearing of Halyomorpha halys}

A $H$. halys colony was established from approximately 80 overwintered adults collected in Zurich and Basel, Switzerland, in 2012, and new individuals from both locations were added on an annual basis. The colony was kept in groups of up to $50 \mathrm{H}$. halys in polyester cages ('BugDorm-4090 Insect Rearing Cage $47.5 \times 47.5 \times 47.5 \mathrm{~cm}$ ', MegaView Science Co. Ltd., Taichung, Taiwan) at $26{ }^{\circ} \mathrm{C}, 70 \% \mathrm{RH}$, and a $16 \mathrm{~L}: 8 \mathrm{D}$ photoperiod. Nymphs and adults were provided with combinations of beans, maize, peanuts and carrots, which were replaced twice a week. A variety of branches from different tree species (e.g. Sorbus aucuparia L., Cornus sanguinea L., Prunus avium L.) was added as food and oviposition substrate during summer. Folded black mesh was added to each rearing cage as an additional oviposition substrate.

\section{Rearing of Anastatus bifasciatus}

The original colony of $A$. bifasciatus was established in 2013 from sentinel $H$. halys egg masses exposed near Fully, Canton of Valais, Switzerland. Adults were maintained in cylindrical plastic containers $(100 \times 115 \mathrm{~mm})$, with a mesh top, which were placed above Petri dishes $(90 \times 20 \mathrm{~mm})$ filled with honey water solution. Parasitoids were fed every second day with honey water via cotton wicks that bridged the Petri dishes with the rearing containers, while undiluted honey droplets were placed on top of the mesh. The containers were maintained in an incubator set at a light/temperature cycle of L $14 \mathrm{~h} / 20{ }^{\circ} \mathrm{C}$ and D $10 \mathrm{~h} / 15{ }^{\circ} \mathrm{C}$. Parasitoids were provided twice a week with $H$. halys egg masses that were either fresh $(<24 \mathrm{~h})$, had been stored at $10{ }^{\circ} \mathrm{C}$ for a maximum of $3 \mathrm{~d}$, or frozen for up to one year at $-80^{\circ} \mathrm{C}$. Egg masses were glued to $2 \times 10 \mathrm{~cm}$ cardboard pieces; frozen eggs were thawed for $30 \mathrm{~min}$ before gluing. Parasitized egg masses were removed and placed in cylindrical plastic containers $(100 \times 50 \mathrm{~mm}) \mathrm{kept}$ at $26{ }^{\circ} \mathrm{C}, 70 \% \mathrm{RH}$, and a 16L:8D photoperiod until adult emergence. Upon the initial establishment of the laboratory colonies, specimens of $A$. bifasciatus were taxonomically identified by Lucian Fusu (University of Iasi, Romania).

\section{Selection, source, and rearing of non-target test species}

Non-target species were selected according to the information on A. bifasciatus hosts available from the literature, phylogenetic relatedness and sympatry of target and nontarget species, phenology, egg size, oviposition site, rareness, and accessibility (Kuhlmann et al. 2006). In total, 28 species were selected, including 19 Lepidoptera and 9 Heteroptera (Table 1). In addition, the tropical Lepidoptera Argema mimosae (Boisduval) (Saturniidae) and a Rothschildia sp. (Saturniidae), producing particularly large eggs, were offered as hosts to investigate the effect of egg size on parasitoid offspring. Non-target Heteroptera were collected as nymphs or adults at various sites in Switzerland and Austria (Table 1), whereas most Lepidoptera species were received as eggs, caterpillars, or pupae from commercial breeders. Caterpillars and pupae were reared to the adult stage to obtain eggs for testing. Some Lepidoptera were collected as adults with a light trap placed near a forest edge on the property of CABI in Delémont, Switzerland. These adults were kept in $50 \times 50 \times 50 \mathrm{~cm}$ gauze cages for oviposition and provided with honey water and their associated host plants as oviposition stimulus if necessary. Heteroptera hosts were reared in the same conditions as described for H. halys; however, for some species the mixed diet described above was replaced with specific host plants required for reproduction. Non-target eggs were collected daily and weighed in groups of 10 as a measurement of their size.

\section{No-choice black box tests}

The aim of this experiment was to determine whether eggs of non-target hosts were suitable for parasitoid development. Host acceptance (= successful oviposition, without considering the suitability for development) was not measured because $A$. bifasciatus females do not mark parasitized eggs, and thus, host acceptance cannot be determined nondestructively. Since the experiment could not be conducted in one day, in each experimental set-up, similar numbers of randomly selected naïve, 4-day-old mated A. bifasciatus females were tested simultaneously on eggs of the target $H$. halys (positive control) and the non-target species selected (Table 1). Each parasitoid female was individually exposed for $24 \mathrm{~h}$ to 10 eggs of either the target or non-target, which were glued to cardboard squares $(35 \times 35 \mathrm{~mm})$ and placed inside small plastic Petri dishes $(54 \times 14 \mathrm{~mm})$. Eggs used were either fresh $(<24 \mathrm{~h})$ or had been stored at $10{ }^{\circ} \mathrm{C}$ for a maximum of 3 days to prevent development. Prior to the experiment newly hatched $A$. bifasciatus females had been 
Table 1 Non-target species test list for Anastatus bifasciatus

\begin{tabular}{|c|c|c|c|c|}
\hline Test species & Selection criteria & Oviposition site & $\begin{array}{l}\text { Origin of laboratory } \\
\text { cultures }\end{array}$ & Stage provided/collected \\
\hline \multicolumn{5}{|l|}{ Order: Heteroptera } \\
\hline \multicolumn{5}{|l|}{ Family: Pentatomidae } \\
\hline $\begin{array}{l}\text { Halyomorpha halys } \\
\text { (Stål) }\end{array}$ & Target & $\begin{array}{l}\text { Underside of leaves of vari- } \\
\text { ous host plants }\end{array}$ & $\begin{array}{l}\text { Zurich and Basel, Swit- } \\
\text { zerland }\end{array}$ & Adults \\
\hline $\begin{array}{l}\text { Carpocoris fuscispinus } \\
\text { (Boheman) }\end{array}$ & $\begin{array}{l}\text { Close relatedness, egg size, } \\
\text { literature host record }\end{array}$ & $\begin{array}{l}\text { Leaves and stalks of Api- } \\
\text { aceae and Asteraceae }\end{array}$ & Delémont, Switzerland & Adults \\
\hline $\begin{array}{l}\text { Dolycoris baccarum } \\
\text { (Linnaeus) }\end{array}$ & $\begin{array}{l}\text { Habitat and host plant over- } \\
\text { lap, close relatedness }\end{array}$ & Upper side of leaves & Delémont, Switzerland & Adults \\
\hline $\begin{array}{l}\text { Eurydema dominulus } \\
\text { (Scopoli) }\end{array}$ & Close relatedness & $\begin{array}{l}\text { Leaves and stalks of Bras- } \\
\text { sicaceae and Apiaceae }\end{array}$ & Delémont, Switzerland & Adults \\
\hline $\begin{array}{l}\text { Graphosoma lineatum } \\
\text { (Linnaeus) }\end{array}$ & Close relatedness & $\begin{array}{l}\text { Stalks and flowers of } \\
\text { Apiaceae }\end{array}$ & Delémont, Switzerland & Adults \\
\hline $\begin{array}{l}\text { Holcostethus strictus } \\
\text { (Fabricius) }\end{array}$ & Close relatedness & Herbs and trees & Vienna, Austria & Adults \\
\hline $\begin{array}{l}\text { Nezara viridula (Lin- } \\
\text { naeus) }\end{array}$ & $\begin{array}{l}\text { Habitat and host plant } \\
\text { overlap, close relatedness, } \\
\text { literature host record }\end{array}$ & $\begin{array}{l}\text { Underside of leaves of vari- } \\
\text { ous host plants }\end{array}$ & Lugano, Switzerland & Nymphs and adults \\
\hline $\begin{array}{l}\text { Palomena prasina (Lin- } \\
\text { naeus) }\end{array}$ & Close relatedness & On host plants & Delémont, Switzerland & Nymphs and adults \\
\hline $\begin{array}{l}\text { Piezodorus lituratus } \\
\text { (Fabricius) }\end{array}$ & Close relatedness & $\begin{array}{l}\text { On stems, leaves and fruits } \\
\text { of Fabaceae }\end{array}$ & Vienna, Austria & Adults \\
\hline \multicolumn{5}{|l|}{ Family: Coreidae } \\
\hline $\begin{array}{l}\text { Coreus marginatus (Lin- } \\
\text { naeus) }\end{array}$ & Relatedness, egg size & On Rumex leaves & Delémont, Switzerland & Adults \\
\hline \multicolumn{5}{|l|}{ Order: Lepidoptera } \\
\hline \multicolumn{5}{|l|}{ Family: Cossidae } \\
\hline $\begin{array}{l}\text { Cossus cossus (Lin- } \\
\text { naeus) }\end{array}$ & $\begin{array}{l}\text { Habitat and host plant } \\
\text { overlap }\end{array}$ & In crevices of tree bark & Commercially obtained & Eggs \\
\hline \multicolumn{5}{|l|}{ Family: Endromidae } \\
\hline $\begin{array}{l}\text { Endromis versicolora } \\
\text { (Linnaeus) }\end{array}$ & $\begin{array}{l}\text { Habitat and host plant } \\
\text { overlap }\end{array}$ & Around thin branches & Commercially obtained & Pupae \\
\hline \multicolumn{5}{|l|}{ Family: Erebidae } \\
\hline Arctia caja (Linnaeus) & $\begin{array}{l}\text { Habitat and host plant } \\
\text { overlap }\end{array}$ & $\begin{array}{l}\text { Underside of host plant } \\
\text { leaves }\end{array}$ & Delémont, Switzerland & Adults \\
\hline $\begin{array}{l}\text { Catocala dilecta (Hüb- } \\
\text { ner) }\end{array}$ & Overwintering as eggs & & Commercially obtained & Eggs \\
\hline $\begin{array}{l}\text { Catocala electa } \\
\text { (Vieweg) }\end{array}$ & $\begin{array}{l}\text { Threatened species in } \\
\text { Germany, overwintering } \\
\text { as eggs }\end{array}$ & & Commercially obtained & Eggs \\
\hline $\begin{array}{l}\text { Lymantria dispar (Lin- } \\
\text { naeus) }\end{array}$ & $\begin{array}{l}\text { Habitat and host plant over- } \\
\text { lap, literature host record }\end{array}$ & On trunks & Commercially obtained & Eggs \\
\hline $\begin{array}{l}\text { Leucoma salicis (Lin- } \\
\text { naeus) }\end{array}$ & Literature host record & On leaves and twigs & Commercially obtained & Eggs \\
\hline \multicolumn{5}{|l|}{ Family: Sphingidae } \\
\hline $\begin{array}{l}\text { Smerinthus ocellata } \\
\text { (Linnaeus) }\end{array}$ & $\begin{array}{l}\text { Habitat and host plant } \\
\text { overlap }\end{array}$ & Underside of leaves & Delémont, Switzerland & Adults \\
\hline Sphinx pinastri Linnaeus & $\begin{array}{l}\text { Egg size, high abundance, } \\
\text { pollinator }\end{array}$ & On needles & Delémont, Switzerland & Adults \\
\hline \multicolumn{5}{|l|}{ Lasiocampidae } \\
\hline $\begin{array}{l}\text { Dendrolimus pini (Lin- } \\
\text { naeus) }\end{array}$ & $\begin{array}{l}\text { Egg size, family with many } \\
\text { literature host records }\end{array}$ & On needles & Commercially obtained & Eggs \\
\hline $\begin{array}{l}\text { Euthrix potatoria (Lin- } \\
\text { naeus) }\end{array}$ & $\begin{array}{l}\text { Egg size, family with many } \\
\text { literature host records }\end{array}$ & On grasses & Bärschwil, Switzerland & Caterpillars \\
\hline
\end{tabular}


Table 1 (continued)

\begin{tabular}{|c|c|c|c|c|}
\hline Test species & Selection criteria & Oviposition site & $\begin{array}{l}\text { Origin of laboratory } \\
\text { cultures }\end{array}$ & Stage provided/collected \\
\hline $\begin{array}{l}\text { Gastropacha quercifolia } \\
\text { (Linnaeus) }\end{array}$ & $\begin{array}{l}\text { Habitat and host plant } \\
\text { overlap, threatened in } \\
\text { Germany }\end{array}$ & Underside of leaves & Commercially obtained & Eggs \\
\hline $\begin{array}{l}\text { Lasiocampa quercus } \\
\text { (Linnaeus) }\end{array}$ & $\begin{array}{l}\text { Habitat and host plant } \\
\text { overlap }\end{array}$ & $\begin{array}{l}\text { Drop eggs on ground dur- } \\
\text { ing flight }\end{array}$ & Delémont, Switzerland & Adults \\
\hline $\begin{array}{l}\text { Malacosoma neustria } \\
\text { (Linnaeus) }\end{array}$ & $\begin{array}{l}\text { Habitat and host plant over- } \\
\text { lap, literature host records }\end{array}$ & Around twigs & Commercially obtained & Eggs \\
\hline $\begin{array}{l}\text { Odonestis pruni (Lin- } \\
\text { naeus) }\end{array}$ & $\begin{array}{l}\text { Habitat and host plant } \\
\text { overlap, endangered in } \\
\text { Germany }\end{array}$ & On leaves & Commercially obtained & Eggs \\
\hline \multicolumn{5}{|l|}{ Family: Notodontidae } \\
\hline $\begin{array}{l}\text { Phalera bucephala (Lin- } \\
\text { naeus) }\end{array}$ & $\begin{array}{l}\text { Habitat and host plant } \\
\text { overlap }\end{array}$ & Underside of leaves & Delémont, Switzerland & Adults \\
\hline \multicolumn{5}{|l|}{ Family: Saturniidae } \\
\hline Samia cynthia (Drury) & $\begin{array}{l}\text { Habitat and host plant } \\
\text { overlap }\end{array}$ & Underside of leaves & Commercially obtained & Pupae \\
\hline $\begin{array}{l}\text { Saturnia pyri (Denis and } \\
\text { Schiffermüller) }\end{array}$ & $\begin{array}{l}\text { Habitat and host plant over- } \\
\text { lap, declining populations }\end{array}$ & Underside of leaves & Commercially obtained & Pupae \\
\hline
\end{tabular}

kept together with males for 4 days at $26^{\circ} \mathrm{C}, 70 \% \mathrm{RH}$, and a 16L:8D photoperiod to ensure mating. Two drops of pure honey and honey water solution were added to the corners of the cardboard to provide the parasitoids with food during the experiment. After $24 \mathrm{~h}$, the wasps were removed, and exposed eggs were checked daily for hatched hosts or parasitoids, which were then counted and sexed. All tests were conducted at $26^{\circ} \mathrm{C}, 70 \% \mathrm{RH}$, and a 16L:8D photoperiod.

\section{Comparison of size, offspring production, and longevity of $A$. bifasciatus reared from different hosts}

To compare the fitness of $A$. bifasciatus reared on target and non-target hosts, the parameters adult size, 48-h offspring production, and longevity were measured. Anastatus bifasciatus offspring that had emerged from the target (controls) and five selected non-target species (D. pini, E. versicolora, L. quercus, O. pruni and S. cynthia) in the nochoice black box experiment were used. For the offspring production experiment, male and female A. bifasciatus were transferred to rearing containers described above immediately after emergence and maintained at $26^{\circ} \mathrm{C}, 70 \% \mathrm{RH}$, and a 16L:8D photoperiod. Wasps that had emerged from different host species were kept separately. Four to 5 days after emergence, $A$. bifasciatus females ( $n=2-16$ per non-target host species) were individually placed in a small plastic Petri dish $(54 \times 14 \mathrm{~mm})$ that contained 10 fresh $(<24 \mathrm{~h}$ old $) H$. halys eggs glued to cardboard squares $(35 \times 35 \mathrm{~mm})$. After $24 \mathrm{~h}$, the wasps were transferred to new Petri dishes with a fresh set of $H$. halys eggs for another $24 \mathrm{~h}$. The number of eggs provided over 2 days was limited to 20, as preliminary experiments had shown that $A$. bifasciatus females could produce no more than 16 offspring within $48 \mathrm{~h}$ [average $7.63 \pm 3.80(\mathrm{SD})]$ (Stahl et al. unpublished data).

For the longevity experiment, pairs of male and female wasps ( $n=5-30$ per host species), each originating from the same non-target host species or $H$. halys (control), were transferred immediately after emergence to plastic tubes (7 $\mathrm{cm}$ height and $3.3 \mathrm{~cm}$ diameter) with a mesh top. Tubes were placed in an incubator set at a light/temperature cycle of $\mathrm{L} 14 \mathrm{~h} / 20^{\circ} \mathrm{C}$ and D $10 \mathrm{~h} / 15^{\circ} \mathrm{C}$. Wasps were provided with honey water solution, and mortality of wasps was recorded daily until all wasps had died. Dead parasitoid wasps were placed in 2-ml microtubes and submerged in 96\% ethanol.

Photographs were taken of randomly chosen, stored specimens with a digital microscope to compare the size of offspring from different hosts and relating size to longevity. The length of their left hind tibia was then measured using the image processing program ImageJ (Rasband 1997). For each host species, twelve male and female parasitoids were measured; if fewer A. bifasciatus offspring had emerged, all available wasps were used.

\section{Statistical analyses}

The proportion of A. bifasciatus females producing offspring on target and non-target hosts in the no-choice black box test was calculated by dividing the number of replicates producing offspring by the total number of replicates conducted. Pairwise comparisons between each non-target species and its respective $H$. halys control were made using a generalized 
linear model (GLM) of the binomial family (link=logit). For some non-target species, no parasitoid females produced offspring. In these cases of complete separation of factor levels, standard methods of logistic regressions are not able to estimate coefficients. For that reason, logistic regression with Firth's bias correction (Heinze and Schemper 2002) was used.

The relationship between the size of the parasitoid offspring and the size of the host eggs they emerged from was measured with a linear regression for females and with a logarithmic regression for males.

Sex ratio was calculated as the percentage of female $A$. bifasciatus offspring for each single egg mass, which were then averaged for each host species. It was tested for dependence on host egg size with logistic regression using GLM (family = binomial, link= logit), number of female offspring as dependent, and the average weight of host eggs as independent variable.

The fecundity of F1 generation females was determined by their offspring production during $48 \mathrm{~h}$. The relationship between the host species the tested parasitoid females emerged from and their offspring production was assessed pairwise with a GLM (family $=$ Poisson, $\operatorname{link}=\log$ ).

Longevity of female offspring of selected host species was defined as number of days until death. The influence of the host species the parasitoids emerged from on their longevity was assessed pairwise for each non-target species and their respective $H$. halys controls with a log-rank test.

All statistics were carried out with $R$ version 3.2.3 (Team 2014) using the development environment RStudio (Team 2017). For the pairwise comparisons of the proportion of A. bifasciatus females producing offspring with Firth's bias correction the package 'logistf' (Ploner 2010) was used and for the Tukey's post hoc 'multcomp' (Hothorn et al. 2008) was applied.

\section{Results}

\section{No-choice black box tests}

Overall, $46.5 \%$ of $A$. bifasciatus females tested produced offspring when offered $H$. halys egg masses (controls). Even though standardized females were used, values for control replicates yielding parasitoid offspring were highly variable, ranging from 13 to $86 \%$ (Fig. 1), and dependent on the testing dates and cohorts of females used.

All ten heteropteran hosts exposed in no-choice tests produced viable $A$. bifasciatus offspring, including the target $H$. halys (Fig. 1a). Only in two species, G. lineatum and P. lituratus, the proportion of females producing viable offspring was significantly lower (binomial GLM, $\mathrm{df}=108, \chi^{2}=6.707$, $p=0.00960 ; \mathrm{df}=71, \chi^{2}=12.5, p<0.001$, respectively) than in the H. halys controls (Online Resource 1). Regarding lepidopteran hosts, fourteen out of nineteen tested species were suitable for parasitoid development. The only species tested from the family Cossidae (C. cossus), and four out of five hosts in the family Erebidae did not produce any offspring (Fig. 1b). Tested species within the families Endromidae, Sphingidae, Lasiocampidae, Notodontidae, Papilionidae, and Saturniidae were all suitable hosts, and for the majority of species the proportion of females producing offspring was as high as in $H$. halys controls (Fig. 1b, c). When offered eggs of $S$. pinastri and $S$. pyri, significantly more females produced offspring than in $H$. halys controls (binomial $\mathrm{GLM}, \mathrm{df}=75, \chi^{2}=4.70, p<0.001$ and $\mathrm{df}=34, \chi^{2}=7.53$, $p=0.006062$, respectively), whereas for M. neustria and E. potatoria it was the opposite (binomial GLM, $\mathrm{df}=59$, $\chi^{2}=10.18, p=0.00141$ and $\mathrm{df}=80, \chi^{2}=26.61, p<0.001$, respectively) (Online Resource 1).

\section{Comparison of size, sex ratio, offspring production, and longevity of $A$. bifasciatus reared from different hosts}

A wide range of offspring sizes as well as a pronounced sexual dimorphism with larger females and smaller males was observed for $A$. bifasciatus when reared from various European hosts (Table 2 and Fig. 2b). The average male hind tibia lengths ranged from $267 \pm 19 \mu \mathrm{m}$ (host: $M$. neustria) to $582 \pm 23 \mu \mathrm{m}$ (host: L. quercus), while in females it ranged from $645.5 \pm 46 \mu \mathrm{m}$ (host: $C$. fuscispinus) to $1084 \pm 28.5 \mu \mathrm{m}$ (host: L. quercus). Even bigger females $(1119.5 \pm 10 \mu \mathrm{m})$ emerged from A. mimosae, a large tropical species. The size of the male and female offspring significantly increased with host egg size (logarithmic regression, $\mathrm{df}=19, t=8.851$, $p<0.001, R^{2}=0.80$ and linear regression, $\mathrm{df}=12, t=25.505$, $p<0.001, R^{2}=0.93$, respectively) (Fig. 2a). Among the heteropteran hosts tested, $H$. halys produced the largest females (Table 2), although still smaller than those emerging from most lepidopteran hosts.

The sex ratio of the offspring was significantly affected by the size of the host (binomial GLM, $\mathrm{df}=600, z=-9.24$, $p<0.001$; Fig. 3). From eggs smaller than $0.7 \mathrm{mg}$ only males emerged, while above this threshold the proportion of female offspring increased with increasing size of host eggs. The highest female-biased sex ratio $(76 \%)$ was received from the large tropical lepidopteran host A. mimosa. The proportion of males (51\%) and females (49\%) emerging from $H$. halys eggs was nearly balanced.

The longevity of individual A. bifasciatus females emerged from the non-target hosts L. quercus, O. pruni, and E. versicolora as well as the target host ranged from 7 to 172 days at a light/temperature cycle of $\mathrm{L} 14 \mathrm{~h} / 20{ }^{\circ} \mathrm{C}$ and $\mathrm{D} 10 \mathrm{~h} / 15^{\circ} \mathrm{C}$ (Fig. 4). Those females that had emerged from the host $L$. quercus, producing the largest eggs of the 

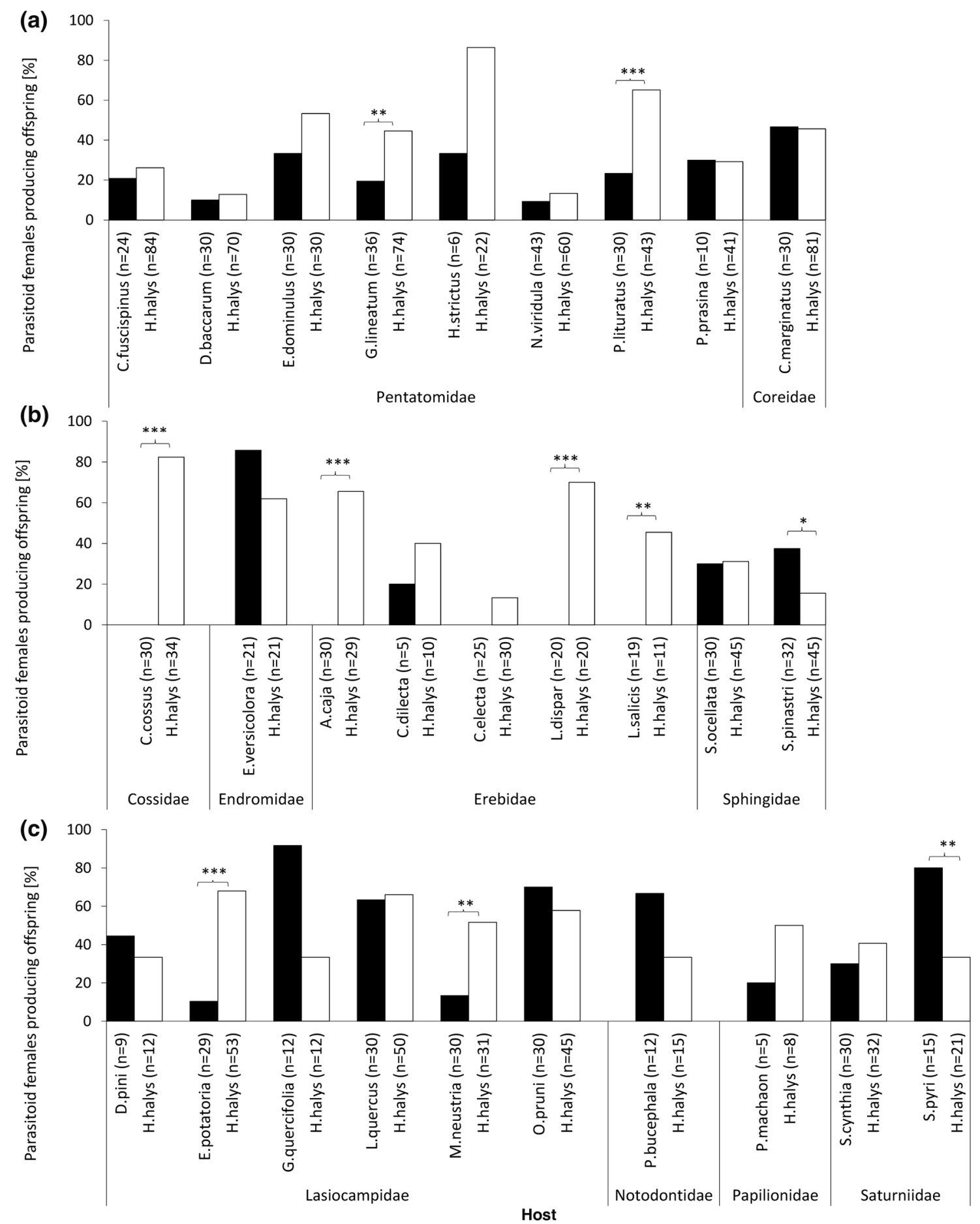

Fig. 1 Percentage of A. bifasciatus females producing offspring from heteropteran (a) and lepidopteran (b, c) non-target hosts (black bars). White bars represent the respective $H$. halys controls. $N$ states the

species tested and accordingly the largest females, lived significantly longer than those emerged from the $H$. halys controls (log-rank test, $\mathrm{df}=1, \chi^{2}=16.4, p<0.001$ ). In contrast, females emerged from $O$. pruni and E. versicolora did not live significantly longer than their controls (log-rank test, number of tested females. Asterisks indicate significant differences between treatment and control $(\mathrm{GLM}$, family $=$ binomial $)$

$\mathrm{df}=1, \chi^{2}=0.3, p=0.577$ and $\chi^{2}=3.1, p=0.0773$, respectively) (Fig. 4).

The offspring production of A. bifasciatus females emerged from non-target species, all of which produced larger females than $H$. halys, was generally higher than the 
Table 2 Mean weight of ten host eggs as estimate of host egg size, sex ratio, and average hind tibia lengths of male and female A. bifasciatus reared from European non-target species, two large tropical host species $(*)$, and the target host $H$. halys

\begin{tabular}{|c|c|c|c|c|c|c|c|c|c|c|}
\hline \multirow[t]{2}{*}{ Order } & \multirow[t]{2}{*}{ Host species } & \multirow[t]{2}{*}{$\begin{array}{l}\text { \# Groups of } 10 \\
\text { eggs weighed }(n)\end{array}$} & \multirow{2}{*}{$\begin{array}{l}\text { Mean weight of } \\
\text { ten eggs } \pm S D \\
(\mathrm{mg})\end{array}$} & \multicolumn{3}{|c|}{ Sex ratio $($ mean $\pm S D)$} & \multicolumn{4}{|c|}{$\begin{array}{l}\text { Average hind tibia length } \pm \text { SD } \\
(\mu \mathrm{m})\end{array}$} \\
\hline & & & & $n$ & Males & Females & $n$ & Males & $n$ & Females \\
\hline \multirow[t]{18}{*}{ Lepidoptera } & L. salicis & 10 & $2.74 \pm 0.28$ & 0 & & & 0 & & 0 & \\
\hline & M. neustria & 10 & $3.53 \pm 0.28$ & 8 & $1.00 \pm 0.00$ & $0.00 \pm 0.00$ & 11 & $265 \pm 16$ & 0 & \\
\hline & A.caja & 10 & $4.48 \pm 0.19$ & 0 & & & 0 & & 0 & \\
\hline & C.electa & 10 & $4.47 \pm 0.41$ & 0 & & & 0 & & 0 & \\
\hline & L. dispar & 10 & $7.89 \pm 0.43$ & 0 & & & 0 & & 0 & \\
\hline & C. cossus & 10 & $8.92 \pm 0.78$ & 0 & & & 0 & & 0 & \\
\hline & O. pruni & 19 & $16.14 \pm 1.02$ & 89 & $0.73 \pm 0.37$ & $0.27 \pm 0.37$ & 12 & $460 \pm 17$ & 8 & $749 \pm 36$ \\
\hline & E. versicolora & 10 & $17.47 \pm 1.09$ & 56 & $0.60 \pm 0.38$ & $0.40 \pm 0.38$ & 12 & $498 \pm 15$ & 12 & $823 \pm 34$ \\
\hline & G. quercifolia & 10 & $17.66 \pm 0.25$ & 33 & $0.70 \pm 0.35$ & $0.30 \pm 0.35$ & 11 & $456 \pm 34$ & 12 & $770 \pm 30$ \\
\hline & S. cynthia & 10 & $18.42 \pm 1.22$ & 38 & $0.79 \pm 0.42$ & $0.21 \pm 0.42$ & 12 & $458 \pm 60$ & 1 & $872 \pm 00$ \\
\hline & S. ocellata & 10 & $19.09 \pm 1.36$ & 57 & $0.78 \pm 0.22$ & $0.22 \pm 0.22$ & 12 & $494 \pm 27$ & 6 & $824 \pm 66$ \\
\hline & Rothschildia sp.* & 2 & $24.40 \pm 0.42$ & 89 & $0.35 \pm 0.28$ & $0.65 \pm 0.28$ & 12 & $443 \pm 44$ & 12 & $761 \pm 67$ \\
\hline & E. potatoria & 10 & $24.74 \pm 0.80$ & 3 & $0.67 \pm 0.58$ & $0.33 \pm 0.58$ & 2 & $478 \pm 13$ & 0 & \\
\hline & S. pinastri & 10 & $32.81 \pm 2.12$ & 64 & $0.46 \pm 0.32$ & $0.54 \pm 0.32$ & 12 & $493 \pm 47$ & 10 & $883 \pm 66$ \\
\hline & D. pini & 9 & $34.50 \pm 1.07$ & 5 & $0.44 \pm 0.43$ & $0.56 \pm 0.43$ & 12 & $427 \pm 44$ & 12 & $1003 \pm 46$ \\
\hline & L. quercus & 32 & $44.97 \pm 3.87$ & 124 & $0.26 \pm 0.09$ & $0.74 \pm 0.09$ & 12 & $559 \pm 27$ & 12 & $1072 \pm 36$ \\
\hline & S. pyri & 4 & $46.58 \pm 2.94$ & 58 & $0.22 \pm 0.16$ & $0.78 \pm 0.16$ & 9 & $561 \pm 39$ & 12 & $1053 \pm 30$ \\
\hline & A. mimosae* & 10 & $48.28 \pm 2.72$ & 46 & $0.24 \pm 0.24$ & $0.76 \pm 0.24$ & 3 & $539 \pm 30$ & 12 & $1085 \pm 32$ \\
\hline \multirow[t]{10}{*}{ Heteroptera } & D. baccarum & 9 & $3.45 \pm 1.06$ & 3 & $1.00 \pm 0.00$ & $0.00 \pm 0.00$ & 12 & $329 \pm 33$ & 0 & \\
\hline & E. dominulus & 3 & $4.17 \pm 0.38$ & 70 & $1.00 \pm 0.00$ & $0.00 \pm 0.00$ & 12 & $342 \pm 14$ & 0 & \\
\hline & P. lituratus & 10 & $4.44 \pm 0.42$ & 41 & $1.00 \pm 0.00$ & $0.00 \pm 0.00$ & 12 & $329 \pm 27$ & 0 & \\
\hline & H. strictus & 8 & $4.53 \pm 0.85$ & 8 & $1.00 \pm 0.00$ & $0.00 \pm 0.00$ & 8 & $326 \pm 32$ & 0 & \\
\hline & N. viridula & 10 & $4.72 \pm 0.18$ & 17 & $1.00 \pm 0.00$ & $0.00 \pm 0.00$ & 12 & $313 \pm 25$ & 0 & \\
\hline & G. lineatum & 10 & $6.98 \pm 0.42$ & 50 & $1.00 \pm 0.00$ & $0.00 \pm 0.00$ & 12 & $394 \pm 18$ & 0 & \\
\hline & C. fuscispinus & 10 & $8.98 \pm 5.28$ & 20 & $0.67 \pm 0.27$ & $0.33 \pm 0.27$ & 12 & $384 \pm 32$ & 7 & $630 \pm 47$ \\
\hline & P. prasina & 3 & $9.13 \pm 0.81$ & 22 & $0.19 \pm 0.17$ & $0.81 \pm 0.17$ & 10 & $424 \pm 23$ & 12 & $676 \pm 59$ \\
\hline & C. marginatus & 10 & $11.01 \pm 0.47$ & 40 & $0.49 \pm 0.34$ & $0.51 \pm 0.34$ & 12 & $463 \pm 22$ & 12 & $740 \pm 31$ \\
\hline & H. halys & 10 & $12.91 \pm 1.25$ & 1079 & $0.51 \pm 0.37$ & $0.49 \pm 0.37$ & 12 & $435 \pm 29$ & 12 & $749 \pm 64$ \\
\hline
\end{tabular}

(a)

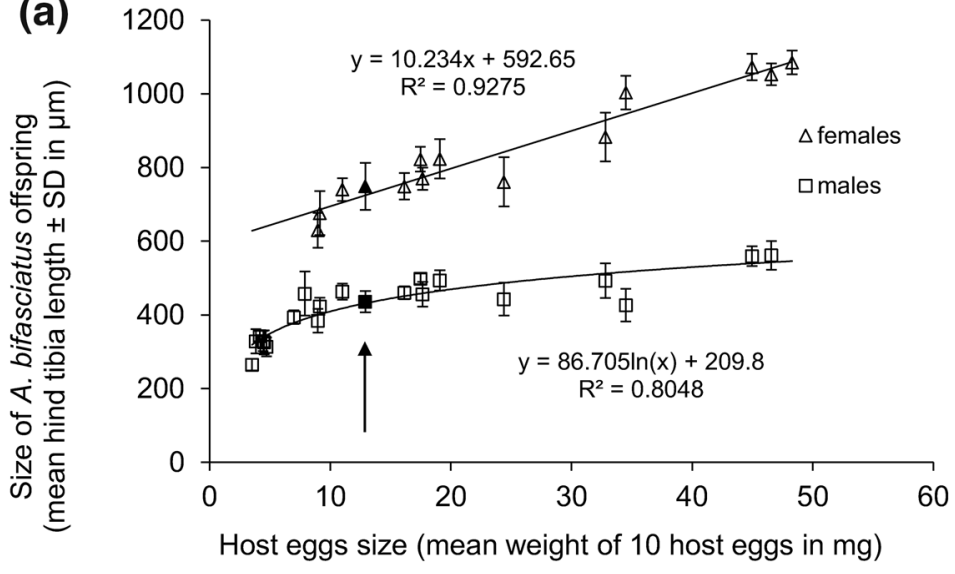

(b)
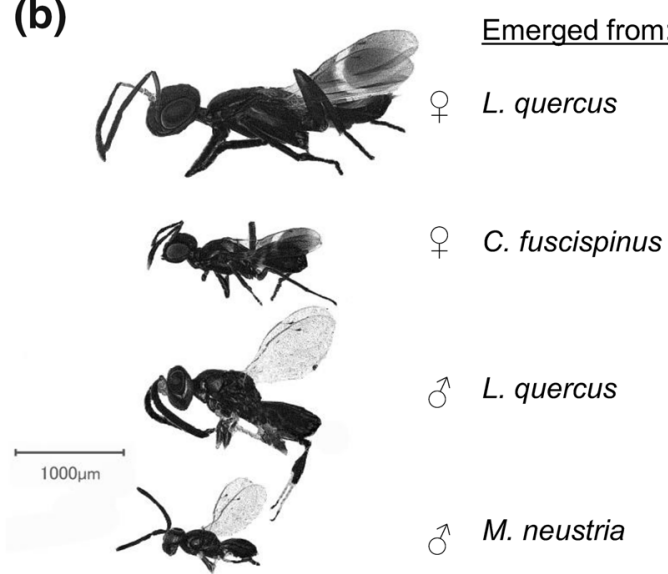

C. fuscispinus

L. quercus

M. neustria
Fig. 2 a Relationship between egg size of different host species, shown as mean weight of 10 host eggs, and the size of the A. bifasciatus offspring (for host species with $\geq 5$ measurements), shown as mean hind tibia length. Black symbols (arrow) represent the values for the target $H$. halys; b sexual dimorphism and influence of host egg size on A. bifasciatus adult size (see Table 2) 


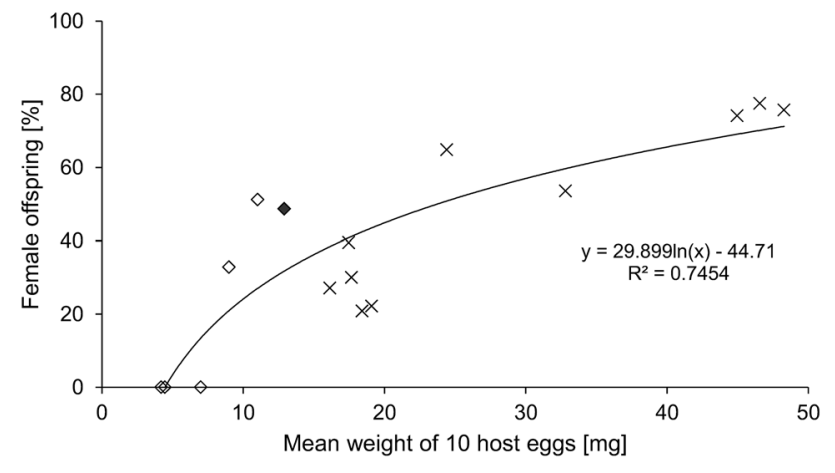

Fig. 3 Relationship between sex ratio of A. bifasciatus offspring emerged from heteropteran (squares) and lepidopteran (crosses) nontarget hosts and size of host eggs expressed as mean weight of 10 host eggs $(\mathrm{GLM}$, family $=$ binomial, $p<0.001)$. Species that generated low numbers of offspring $(<20$ individuals, see Table 2$)$ were not included in the analysis; $H$. halys is marked black

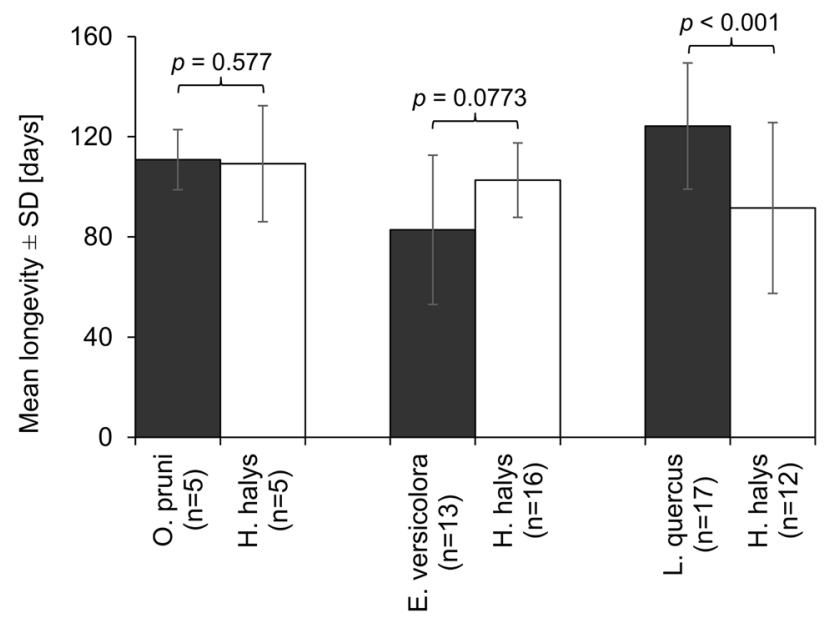

Fig. 4 Mean longevity of A. bifasciatus females reared from three non-target species (black bars) and the target $H$. halys (white bars) at a light/temperature cycle of $\mathrm{L} 14 \mathrm{~h} / 20{ }^{\circ} \mathrm{C}$ and $\mathrm{D} 10 \mathrm{~h} / 15{ }^{\circ} \mathrm{C}$. $N$ is the number of females tested; the mean weight of ten eggs in $\mathrm{mg}(H$. halys $=12.91$, O. pruni $=16.14$, E. versicolora $=17.47, \mathrm{~L}$. quercus $=44.97$ ) is mentioned as indicator for host egg size (see Table 2). $P$ values are indicated on top of the compared pairs (logrank test)

offspring production of females emerged from $H$. halys (Fig. 5), but only for those emerged from S. cynthia and L. quercus, the difference was significant (Poisson GLM, $\mathrm{df}=5, z=3.14, p<0.001$ and $\mathrm{df}=10, z=2.26, p=0.0254$, respectively). For the other two non-targets, $O$. pruni and $D$. pini, the difference showed no statistical significance (Poisson GLM, $\mathrm{df}=17, z=0.799, p=0.424$ and $\mathrm{df}=4$, $z=-1.601, p=0.1057$, respectively). No significantly different offspring production could be found between females emerged from non-target hosts (Poisson GLM, $\mathrm{df}=18, z=1.15, p>0.05)$.

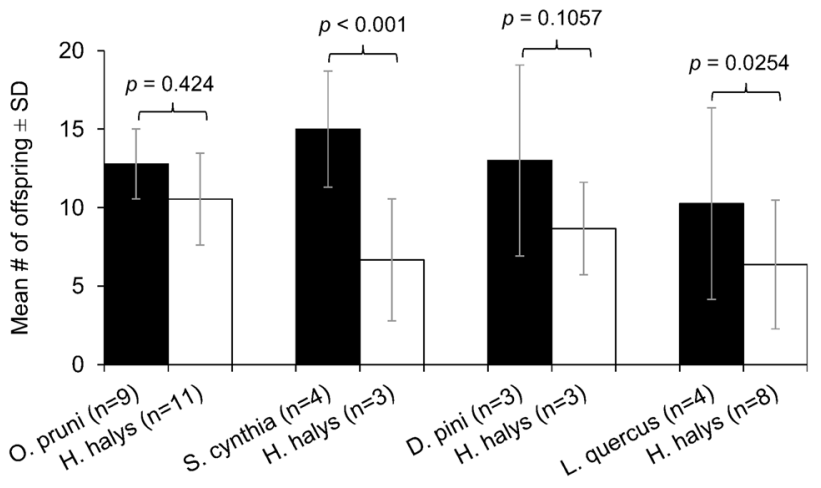

Fig. 5 Mean offspring production of A. bifasciatus females originating from different host species, when offering $2 \times 10 \mathrm{H}$. halys eggs over $2 \times 24 \mathrm{~h}$ consecutively. Black bars represent offspring production of females emerged from non-target hosts and white bars offspring emergence of females emerged from $H$. halys (control). Females emerged from $H$. halys are smallest in size within this group (see Table 2). $\mathrm{N}$ states the number of tested females. $P$ values are indicated on top of the compared pairs (GLM, family=gamma; post hoc Tukey)

\section{Discussion}

Assessing the host range of potential biological control agents is a major step in risk analysis when exotic natural enemies are concerned, but also needs to be considered in inundative biological control with native candidates (van Lenteren and Loomans 2006). If large quantities of a biological control agent are released, these may affect not only the target but also populations of non-target hosts in the target habitat and surrounding habitats due to dispersal behaviour (van Lenteren and Loomans 2006).

Surveys for native natural enemies attacking the invasive brown marmorated stink bug in Europe showed that the egg parasitoid A. bifasciatus is a potential candidate for inundative releases to mitigate damage in European fruit orchards due to oviposition peaks of $H$. halys (Haye et al. 2014a, b). However, even though knowledge on its specific host range and host specificity is scarce, A. bifasciatus has been reared from more than 30 hosts in the orders Heteroptera and Lepidoptera (Noyes 2014) and thus can be considered a polyphagous parasitoid.

In laboratory no-choice tests, developmental suitability of non-target host species for A. bifasciatus was demonstrated by the successful production of progeny on 23 out of 28 tested non-target host species. Five out of seven species that were previously recorded as host of A. bifasciatus in the literature were confirmed: $N$. viridula (Genduso 1977; Jones 1988), D. pini, G. quercifolia, M. neustria and S. pyri (Herting and Simmonds 1976) (Fig. 1). In contrast, L. dispar and L. salicis (Erebidae) were not suitable hosts (Fig. 1), although they had been recorded as hosts for A. bifasciatus in Turkey (e.g. Avci 2009; Herting and Simmonds 1976) and 
in Eastern Europe (Boucek 1977; Zaharieva-Pentcheva and Georgiev 1997), respectively. In agreement with the present study, Hayat (1975) suggested that $L$. dispar is not a suitable host for A. bifasciatus, referring to the common confusion of Anastatus japonicus Ashmead with A. bifasciatus. Meanwhile, eight new heteropteran hosts in two families and eleven lepidopteran hosts in six families can be added to the fundamental host range of A. bifasciatus (Fig. 1), confirming its highly polyphagous nature.

Apart from the Cossidae family, represented by only one species, all families tested included suitable host species. Overall, the majority of non-target species tested was as suitable as the target $H$. halys, while in two cases, S. pinastri and $S$. pyri, the proportion of females producing offspring was even higher than for the target. Interestingly, only one out of five species within the family Erebidae produced parasitoid offspring. Similar results were found for the generalist Trichogramma brassicae Bezdenko (Babendreier et al. 2003a), indicating that the taxonomy of potential host species is not the only criteria of host selection for generalist parasitoids. There are various reasons why certain species may not have been suitable for parasitoid development: eggs within the families Cossidae and Erebidae were all relatively small $(<1 \mathrm{mg})$ and may not provide enough resources for successful offspring development. On the other hand, heteropteran hosts with eggs smaller than $1 \mathrm{mg}$ were frequently accepted, even if only male offspring was produced. Another explanation could be that some eggs may have been protected by morphological or chemical defences as demonstrated for the moth Zygaena trifolii (Esper) (Lepidoptera: Zygaenidae) whose eggs contain toxic substances (Marsh and Rothschild 1974). Eggs of some Erebidae are naturally covered in either hairs (L. dispar), a paper like substance ( $L$. salicis) or contain high concentrations of choline esters $(A$. caja), which can prevent parasitism (Morley and Schachter 1963, Ohta et al. 1994). The materials covering the host eggs of $L$. dispar and $L$. salicia were removed before the experiments, which could negate their parasitism-inhibiting effects (Darling and Johnson 1982), but residual traces may still have led to the rejection of the eggs by A. bifasciatus. In contrast, the only species in the family Erebidae that produced offspring was $C$. dilecta, which is not protected by any of the factors described above.

Considering the continuous rearing of the A. bifasciatus colony on $H$. halys for about 35 generations, a shift in host preference may have led to an underestimation of $A$. bifasciatus females producing offspring on non-target species in comparison with natural $A$. bifasciatus populations or parasitoids reared on factitious hosts. In general, the proportion of A. bifasciatus females producing offspring when given eggs of the target $H$. halys was extremely variable. Since only little is known on the reproductive biology of this species, it is possible that, for example, using older or experienced females may have resulted in more consistent data across the controls.

The sex ratio of $A$. bifasciatus offspring was strongly dependent on the host egg size. Lepidopteran and heteropteran hosts with an egg size below $0.7 \mathrm{mg}$ only produced male offspring. In hosts with eggs ranging from 0.9 to $1.9 \mathrm{mg}$ the sex ratio was heavily male biased, whereas eggs larger than $4 \mathrm{mg}$ produced significantly more females. Our results agree with the theory of conditional sex allocation, where the parasitoid offspring shifts towards a female bias with increasing host quality (Charnov 1979; Charnov et al. 1981). In line with our findings, also Hou et al. (2009) reported a more female-biased sex ratio when Anastatus sp. was reared on eggs of oak silkworm (Antheraea pernyi (Guérin-Méneville), Lepidoptera: Saturniidae) instead of $H$. halys. While the sex ratio of the parasitoid offspring has no immediate effect on the efficacy of inundative releases against $H$. halys, the attack of non-target species yielding only male offspring would prevent the development of successive generations on a given non-target species, thereby limiting population-level non-target effects beyond a single generation.

For $H$. halys, the heteropteran species with the largest eggs tested $(1.29 \mathrm{mg})$, the sex ratio was balanced, indicating that $H$. halys is a medium-quality host. However, most similar sized lepidopteran eggs yielded a less female-biased sex ratio of about $20-40 \%$ female offspring, providing some evidence that the quality of lepidopteran eggs is assessed as less good by A. bifasciatus compared to heteropteran hosts. Obviously, host quality was strongly correlated with host size, since larger host eggs yielded larger parasitoid offspring, which in turn profit from fitness advantages over smaller conspecifics (Arakawa et al. 2004; Medal and Smith 2015). The sexual dimorphism of A. bifasciatus with larger females and smaller males was more pronounced with increasing host egg size. A stronger correlation was observed for females, which may be explained by the fact that female fecundity is more dependent on size than male mating success (Morris and Fellowes 2002; Van den Assem 1970).

In many host-parasitoid systems female fecundity and longevity are positively correlated with female body size (Godfray 1994). In addition, Visser (1994) showed a positive correlation between female size and other fitness parameters like egg-carrying capacity, egg size, and females' searching efficiency for the parasitoid Aphaereta minuta (Nees) (Hymenoptera: Braconidae). All of these are desirable attributes for biological control agents, and accordingly releasing 'fitter' females may increase the success of inundative biological control. In the present study, we did not measure the lifetime fecundity of different sized females, but it was demonstrated that larger females, which had emerged from larger lepidopteran eggs, tended to produce more offspring 
within $48 \mathrm{~h}$ than their smaller conspecifics emerged from $H$. halys eggs. In addition, females reared on larger lepidopteran hosts (shown for L. quercus) lived longer than smaller females reared from $H$. halys eggs. Consequently, using lepidopteran hosts with eggs much larger than those of $H$. halys for mass producing A. bifasciatus may be the better approach to maximize the fitness of the solitary parasitoids and thus the effectiveness of inundative releases, an approach that was also followed for rearing other Anastatus spp. against heteropteran pests (Fay and De Faveri 1997; Huang et al. 1974). However, rearing a biological control agent on an alternative host may also alter its host preference (Corrigan and Laing 1994; Henter et al. 1996).

Past examples suggest that even polyphagous parasitoids, which showed a broad host range in the laboratory, can be used for inundative releases because the parasitoid's behaviour in the field indicates low risks for non-target species (Babendreier et al. 2003a, b; Haye et al. 2005). Even if nontarget species are attacked not only in laboratory conditions but also in the field, it does not necessarily translate to a threat to their population (Van Lenteren et al. 2006; van Lenteren and Loomans 2006). A key feature in the assessment of risks in the field under these circumstances is dispersal behaviour, which still is not well understood for $A$. bifasciatus. In case future studies show that it will disperse frequently from the release area into natural adjacent habitats, negative impacts on some non-target species seem possible. Our data suggest that particularly large lepidopteran hosts such as L. quercus and the endangered S. pyri, producing a heavily female-biased offspring, would be 'optimal' hosts and could be negatively affected. In contrast, species producing eggs with a weight of $0.7 \mathrm{mg}$ or smaller, including nearly all heteropteran non-target species tested, would only produce male offspring and would not contribute to population growth of the parasitoid. Even though an exact threshold is difficult to calculate, our data suggest that any non-target species having eggs smaller than $0.3 \mathrm{mg}$ would not be accepted as host and thus not at risk.

Besides these direct effects, the arrival of an invasive species such as $H$. halys may also indirectly affect populations and communities of native species via the sharing of natural enemies, a process referred to as apparent competition (Holt 1977). Since A. bifasciatus is native to Europe and regularly reared from $H$. halys in the field, it is possible that in regions where $H$. halys densities are particularly high, the parasitoid will build up large populations on the exotic hosts, which then may also cause declines of local insect communities. Although apparent competition is recognized as an important factor structuring insect communities (e.g. Bompard et al. 2013; Bonsall and Hassell 1998; Morris et al. 2004), increasing A. bifasciatus populations have not yet been observed in areas invaded by $H$. halys. Continuous inundative releases may accelerate local population growth, making apparent competition more likely, particularly if highly suitable lepidopteran hosts are present in the area of release or nearby.

A better understanding of the predictability of such ecological interactions between $H$. halys and A. bifasciatus can only be accomplished by increasing our knowledge on the reproductive biology, behavioural ecology, and dispersal of A. bifasciatus. The results of this study indicate that non-target effects cannot be ruled out, but expanding the laboratory nontarget studies to semi-field and field conditions will help to better understand potential risks of inundative releases of this native parasitoid.

\section{Author contribution}

DB, JS, and TH conceived and designed research. JS and TH conducted experiments. JS analysed data. JS wrote the manuscript, and DB and TH edited it. All authors read and approved the manuscript.

Acknowledgements The authors are grateful to Serge Fischer (Agroscope Changins-Wädenswil, Switzerland) for providing the original $A$. bifasciatus colony. We would like to thank Warren Wong and Patrick Mrazek for technical assistance in the laboratory. We appreciate the taxonomic guidance offered by Lucian Fusu (University of Iasi, Romania). We would like to thank Hannes Baur (Natural History Museum Bern, Switzerland) for providing the technical equipment for parasitoid measurements. This project has received funding from the European Union's Horizon 2020 research and innovation programme under the Marie Sklodowska-Curie Grant Agreement No 641456. CABI is an international intergovernmental organization, and we gratefully acknowledge the core financial support from our member countries (and lead agencies) including the UK (Department for International Development), China (Chinese Ministry of Agriculture), Australia (Australian Centre for International Agricultural Research), Canada (Agriculture and Agri-Food Canada), Netherlands (Directorate-General for International Cooperation), and Switzerland (Swiss Agency for Development and Cooperation). See http://www.cabi.org/about-cabi/ who-we-work-with/key-donors/ for full details.

\section{Compliance with ethical standards}

Conflict of interest The authors have declared that no conflict of interest exists.

Informed consent Informed consent was obtained from all individual participants included in the study.

Human and animal rights This article does not contain any studies with human participants or animals (vertebrates) performed by any of the authors.

Open Access This article is distributed under the terms of the Creative Commons Attribution 4.0 International License (http://creativeco mmons.org/licenses/by/4.0/), which permits unrestricted use, distribution, and reproduction in any medium, provided you give appropriate credit to the original author(s) and the source, provide a link to the Creative Commons license, and indicate if changes were made. 


\section{References}

Abram PK, Hoelmer KA, Acebes-Doria A et al (2017) Indigenous arthropod natural enemies of the invasive brown marmorated stink bug in North America and Europe. J Pest Sci 90:1009-1020

Arakawa R, Namura Y (2002) Effects of temperature on development of three Trissolcus spp. (Hymenoptera: Scelionidae), egg parasitoids of the brown marmorated stink bug, Halyomorpha halys (Hemiptera: Pentatomidae) (Physiology, Biochemistry, Development and Genetics). Entomol Sci 5:215-218

Arakawa R, Miura M, Fujita M (2004) Effects of host species on the body size, fecundity, and longevity of Trissolcus mitsukurii (Hymenoptera: Scelionidae), a solitary egg parasitoid of stink bugs. Appl Entomol Zool 39:177-181

Askew A (2005) A new European species of anastatus motschulsky (Hym., Eupelmidae). Entomol Mag 141:215

Avci M (2009) Parasitoid complex and new host plants of the gypsy moth, Lymantria dispar L. in the Lakes District, Turkey. J Anim Vet Adv 8:1402-1405

Babendreier D, Kuske S, Bigler F (2003a) Non-target host acceptance and parasitism by Trichogramma brassicae Bezdenko (Hymenoptera: Trichogrammatidae) in the laboratory. Biolog Control 26:128-138

Babendreier D, Kuske S, Bigler F (2003b) Parasitism of non-target butterflies by Trichogramma brassicae Bezdenko (Hymenoptera: Trichogrammatidae) under field cage and field conditions. Biolog Control 26:139-145

Barratt B, Howarth F, Withers T, Kean J, Ridley G (2010) Progress in risk assessment for classical biological control. Biolog Control $52: 245-254$

Bigler F, Babendreier D, Kuhlmann U (2006) Environmental impact of invertebrates for biological control of arthropods: methods and risk assessment. CABI, Wallingford

Bompard A, Jaworski CC, Bearez P, Desneux N (2013) Sharing a predator: can an invasive alien pest affect the predation on a local pest? Pop Ecol 55(3):433-440

Bonsall MB, Hassell MP (1998) Population dynamics of apparent competition in a host-parasitoid assemblage. J Anim Ecol 67:918-929

Bosco L, Moraglio ST, Tavella L (2017) Halyomorpha halys, a serious threat for hazelnut in newly invaded areas. J Pest Sci 91:1-10

Boucek Z (1977) A faunistic review of the Yugoslavian Chalcidoidea (parasitic Hymenoptera). Acta Entomol Serb 13:61

Charnov EL (1979) The genetical evolution of patterns of sexuality: Darwinian fitness. Am Nat 113:465-480

Charnov EL, Los-den Hartogh R, Jones W, Van den Assem J (1981) Sex ratio evolution in a variable environment. Nature 289:27

Chen Y, Lin L, Chen J (1990) Preliminary report of study on the release of Anastatus for the control of the stink bug (Tessaratoma papillosa). Fujian Agr Sci Tech 2:15-16

Corrigan J, Laing J (1994) Effects of the rearing host species and the host species attacked on performance by Trichogramma minutum Riley (Hymenoptera: Trichogrammatidae). Environ Entomol 23:755-760

Crossman SS (1925) Two imported egg parasites of the gipsy moth, Anastatus bifasciatus Fonsc. and Schedius kuvanae Howard. J Agric Res 30(7):643-675

Darling D, Johnson N (1982) Egg mortality in the eastern tent caterpillar, Malacosoma americanum (Lepidoptera: Lasiocampidae): the role of accessory gland secretions and egg mass shape [Hymenopteran parasitoids]. Proc Entomol Soc Wash

Faúndez E, Rider DA (2017) The brown marmorated stink bug Halyomorpha halys (Stål, 1855) (Heteroptera: Pentatomidae) in Chile. Arq Entomolóxicos 17:305-307
Fay H, De Faveri S (1997) Egg parasitoids of fruitspotting bugs (Amblypelta spp.): potential for their mass-rearing and strategic release. Final report HG308:23

Genduso P (1977) Difesa del nocciolo dagli artropodi dannosi. IX. Osservazioni sulla morfologia degli stadi preimmaginali e notizie bio-etologiche dell'Anastatus bifasciatus (Geoffroy). Bollettino dell'Istituto di Entomologia Agraria e dell'Osservatorio di Fitopatologia di Palermo 9:1-22

Godfray HCJ (1994) Parasitoids: behavioral and evolutionary ecology. Princeton University Press, Princeton

Govender AW (2015) Australian fruitspotting bugs, Amblypelta nitida Stål and A. lutescens lutescens Distant (Hemiptera: Coreidae), and the potential for their biologically based management in macadamia orchards. Dissertation, University of Queensland

Hayat M (1975) Some Indian species of Anastatus (Hymenoptera: Chalcidoidea, Eupelmidae). Oriental Insects 9:261-271

Haye T, Goulet H, Mason P, Kuhlmann U (2005) Does fundamental host range match ecological host range? A retrospective case study of a Lygus plant bug parasitoid. Biolog Control 35:55-67

Haye T, Abdallah S, Gariepy T, Wyniger D (2014a) Phenology, life table analysis and temperature requirements of the invasive brown marmorated stink bug, Halyomorpha halys, in Europe. J Pest Sci $87: 407-418$

Haye T, Wyniger D, Gariepy T (2014b) Recent range expansion of brown marmorated stink bug in Europe. In: Proceedings of the 8th international conference on Urban Pests, pp 309-314

Haye T, Fischer S, Zhang J, Gariepy T (2015) Can native egg parasitoids adopt the invasive brown marmorated stink bug, Halyomorpha halys (Heteroptera: Pentatomidae), in Europe? J Pest Sci 88:693-705

Heinze G, Schemper M (2002) A solution to the problem of separation in logistic regression. Stat Med 21:2409-2419

Henter HJ, Brasch K, Lenteren JC (1996) Variation between laboratory populations of Encarsia formosa in their parasitization behavior on the host Bemisia tabaci. Entomol Exp Appl 80:435-441

Herting B, Simmonds FJ (1976): A catalogue of parasites and predators of terrestrial arthropods. Section A. Host or prey/enemy. Vol. VII. Lepidoptera, Part 2 Macrolepidoptera. C.A.B., Farnham

Hoebeke ER, Carter ME (2003) Halyomorpha halys (Stál)(Heteroptera: Pentatomidae): a polyphagous plant pest from Asia newly detected in North America. Proc Entomol Soc Wash 105:225-237

Holt RH (1977) Predation, apparent competition, and the structure of prey communities. Academic Press, New York

Holt RD, Bonsall MB (2017) Apparent Competition. Annu Rev Ecol Evol Syst 48:447-471

Hothorn T, Bretz F, Westfall P (2008) Simultaneous inference in general parametric models. Biom J 50:346-363

Hou Z, Liang H, Chen Q, Hu Y, Tian H (2009) Application of Anastatus sp. against Halyomorpha halys. Forest Pest and Disease 4:39-43

Huang M, Mai S, Wu W, Poo C (1974) The bionomics of Anastatus sp. and its utilization for the control of lichee stink bug Tessaratoma papillosa Drury. Acta Entomol Sin 17:362-375

Huwer R, Maddox CDA, Fay H et al. (2011) A multi target approach to fruitspotting bug management. Research agreement MT10049:50

Jones WA (1988) World review of the parasitoids of the southern green stink bug, Nezara viridula (L.)(Heteroptera: Pentatomidae). Ann Entomol Soc Am 81:262-273

Kobayashi T (1967) The developmental stages of some species of the Japanese Pentatomoidea (Hemiptera): XVI. Homalogonia and an allied genus of Japan (Pentatomidae). Appl Entomol Zool 2:1-8

Kriticos DJ, Kean JM, Phillips CB, Senay SD, Acosta H, Haye T (2017) The potential global distribution of the brown marmorated stink bug, Halyomorpha halys, a critical threat to plant biosecurity. J Pest Sci 90:1033-1043 
Kuhar TP, Kamminga K (2017) Review of the chemical control research on Halyomorpha halys in the USA. J Pest Sci 90:1021-1031

Kuhar TP, Kamminga K, Whalen J et al (2012) The pest potential of brown marmorated stink bug on vegetable crops. Plant Health Prog. https://doi.org/10.1094/PHP-2012-0523-01-BR

Kuhlmann U, Schaffner U, Mason PG (2006) Selection of non-target species for host specificity tests. In: Bigler F, Babendreier D, Kuhlmann U (eds) Environmental impact of invertebrates for biological control of arthropods: methods and risk assessment. CABI Publishing, Wallingford, pp 15-37

Lee D-H, Short BD, Joseph SV, Bergh JC, Leskey TC (2013) Review of the biology, ecology, and management of Halyomorpha halys (Hemiptera: Pentatomidae) in China, Japan, and the Republic of Korea. Environ Entomol 42:627-641

Leskey TC, Hamilton GC, Nielsen AL et al (2012a) Pest status of the brown marmorated stink bug, Halyomorpha halys in the USA. Outlooks Pest Manag 23:218-226

Leskey TC, Short BD, Butler BR, Wright SE (2012b) Impact of the invasive brown marmorated stink bug, Halyomorpha halys (Stål), in mid-Atlantic tree fruit orchards in the United States: case studies of commercial management. Psyche: J Entomol 2012

Lynch L, Hokkanen HMT, Babendreier D et al (2001) Insect biological control and non-target effects: perspective. In: Wajnberg E, Scott JK, Quimby PC (eds) Evaluating indirect ecological effects of biological control. CABI, Wallingford, p 99

Maistrello L, Vaccari G, Caruso S et al (2017) Monitoring of the invasive Halyomorpha halys, a new key pest of fruit orchards in northern Italy. J Pest Sci 90:1231-1244

Marsh N, Rothschild M (1974) Aposematic and cryptic Lepidoptera tested on the mouse. J Zool 174:89-122

Medal J, Smith T (2015) Reversible polyphenism in Trissolcus japonicus (Hymenoptera: Platygastridae) induced by stink bug egg size. J Entomol Sci 50:363-366

Morley J, Schachter M (1963) Acetylcholine in non-nervous tissues of some Lepidoptera. J Physiol 168:706-715

Morris R, Fellowes M (2002) Learning and natal host influence host preference, handling time and sex allocation behaviour in a pupal parasitoid. Behav Ecol Sociobiol 51:386-393

Morris R, Lewis OT, Godfray HCJ (2004) Experimental evidence for apparent competition in a tropical forest food web. Nature 428(6980):310

Narasimham AU, Sankaran T (1982) Biology of Anastatus umae (Hymenoptera: Eupelmidae), an oothecal parasite of Neostylopyga rhombifolia. Colemania 1:135-140

Nielsen AL, Hamilton GC (2009) Seasonal occurrence and impact of Halyomorpha halys (Hemiptera: Pentatomidae) in tree fruit. $\mathbf{J}$ Econ Entomol 102:1133-1140

Nielsen AL, Shearer PW, Hamilton GC (2008) Toxicity of insecticides to Halyomorpha halys (Hemiptera: Pentatomidae) using glass-vial bioassays. J Econ Entomol 101:1439-1442

Noyes J (2014) Universal Chalcidoidea Database-World Wide Web electronic publication. Natural History Museum Update August. http://www.nhm.ac.uk/our-science/data/chalcidoids/. Accessed 03 Jan 2018
Ohta I, Miura K, Kobayashi M (1994) Effect of the scale-hair of the common cutworm egg mass on the oviposition behavior of Trichogramma chilonis Ishii (Hymenoptera: Trichogrammatidae). Appl Entomol Zool 29:608-609

Ploner M (2010) logistf: Firth's bias reduced logistic regression. R package version 1.10. https://cran.r-project.org/web/packages/ logistf/index.html

Rasband WS (1997) ImageJ. US National Institutes of Health, Bethesda

Roversi PF, Marianelli L, Costi E, Maistrello L, Sabbatini PG (2016) Searching for native egg-parasitoids of the invasive alien species Halyomorpha halys Stål (Heteroptera Pentatomidae) in Southern Europe. Redia 99:63

Shrestha R (2011) Productivity improvement of citrus fruits through effective fruit drop management technique in the mid and far western development region of Nepal. Technical report

Talamas EJ, Johnson NF, Buffington M (2015) Key to Nearctic species of Trissolcus Ashmead (Hymenoptera, Scelionidae), natural enemies of native and invasive stink bugs (Hemiptera, Pentatomidae). J Hymenopt Res 43:45

Team RC (2014) R Foundation for Statistical Computing; 2015 R: A language and environment for statistical computing

Team RS (2017) RStudio: integrated development environment for R. RStudio, Inc. 2015

Van den Assem J (1970) Some experiments on sex ratio and sex regulation in the pteromalid Lariophagus distinguendus. Neth J Zool 21:373-402

Van Lenteren JC, Loomans AJ (2006) Environmental risk assessment: methods for comprehensive evaluation and quick scan. In: Bigler F, Babendreier D, Kuhlmann U (eds) Environmental impact of invertebrates for biological control of arthropods: methods and risk assessment. CABI Publishing, Wallingford, pp 254-272

Van Lenteren JC, Bale J, Bigler F, Hokkanen H, Loomans A (2006) Assessing risks of releasing exotic biological control agents of arthropod pests. Ann Rev Entomol 51:609-634

Visser ME (1994) The importance of being large: the relationship between size and fitness in females of the parasitoid Aphaereta minuta (Hymenoptera: Braconidae). J Anim Ecol 963-978

Wermelinger B, Wyniger D, Forster B (2008) First records of an invasive bug in Europe: Halyomorpha halys Stal (Heteroptera: Pentatomidae), a new pest on woody ornamentals and fruit trees? Mitteilungen der Schweizerischen Entomologischen Gesellschaft $81: 1$

Yang Z-Q, Yao Y-X, Qiu L-F, Li Z-X (2009) A new species of Trissolcus (Hymenoptera: Scelionidae) parasitizing eggs of Halyomorpha halys (Heteroptera: Pentatomidae) in China with comments on its biology. Ann Entomol Soc Am 102:39-47

Zaharieva-Pentcheva A, Georgiev G (1997) Parasitoids of the satin moth Stilpnotia salicis (L.)(Lepidoptera, Lymantriidae) in Bulgaria. Bolle Zool Agr Bach 29:81-90

Zhang J, Zhang F, Gariepy T, Mason P, Gillespie D, Talamas E, Haye $\mathrm{T}$ (2017) Seasonal parasitism and host specificity of Trissolcus japonicus in northern China. J Pest Sci 1-15

Zhu G, Gariepy TD, Haye T, Bu W (2017) Patterns of niche filling and expansion across the invaded ranges of Halyomorpha halys in North America and Europe. J Pest Sci 90:1045-1057 